\title{
LIST OF TABLES, FIGURES AND BOXES
}

Tables

TABLE 1.1 Trends in population/demographic indicators in the United States, selected years 5

TABLE 1.2 Macroeconomic indicators, United States, selected years 5

TABLE 1.3 Mortality and health indicators, United States, selected years 12

TABLE 1.4 Life expectancy (years), OECD countries, selected years 13

TABLE 1.5 Infant, neonatal and postneonatal mortality rates in the United States, selected years $\quad 15$

TABLE 1.6 Infant Mortality, OECD Countries, selected years (deaths per 1000 live births) 16

TABLE 1.7 Potential years of life lost, OECD countries, selected years 18

TABLE 1.8 Leading causes of death in the United States, 1980 and $2015 \quad 19$

TABLE 1.9 Cancer survival rates (percentages) among the US population 23

TABLE 1.10 Percentage of people in the United States aged 15 and over who were cigarette smokers (age adjusted), selected years 24

TABLE 1.11 Health indicators affected by health behaviours 24

TABLE 1.12 Obesity among adolescents, percentages, selected years 26

TABLE 1.13 Substance use among the population aged 12 and older, $2015 \quad 27$

TABLE 2.1 Healthy People 2020 topic areas 61

TABLE 3.1 Trends in US national health expenditures, selected years 99

TABLE 3.2 Distribution of health expenditures by type of expenditure, selected years

TABLE 3.3 National health expenditures by condition and service, selected years 
TABLE 3.4 Distribution of health expenditures by source of revenue, selected years

TABLE 3.5 Major sources of health coverage in the United States in 2017

TABLE 3.6 Personal healthcare expenditures, by source of funds and type of expenditure: United States, selected years, 1980-2015

TABLE 3.7 Payment mechanisms for health services

TABLE 4.1 Number of selected types of healthcare facilities in the United States, 1980-2015

TABLE 4.2 Acute-care hospital beds per 1000 population in seven OECD countries, 2000-2016

TABLE 4.3 Average length of stay in acute-care hospitals in seven OECD countries, 1990-2016

TABLE 4.4 Numbers of CT scanners and MRI units per million population in seven OECD countries, 1990-2017

TABLE 4.5 Employed US healthcare personnel per 100000 population, 2000-2017

TABLE 5.1 Utilization of community hospital services in the United States, 1980-2015

TABLE 7.1 Cost-related access problems in past year, 2016

TABLE 7.2 Adults' experiences with access to healthcare in 11 high-income countries, 2016

TABLE 7.3 Problems with health insurance in the last year (\%), 2016345

TABLE 7.4 Immunization rates for selected diseases, 2016350

TABLE 7.5 Cancer screening rates, 2014352

$\begin{array}{lll}\text { TABLE 7.6 Coordinated care, } 2016 & 359\end{array}$

TABLE 7.7 Safe care, 2015 or $2016 \quad 359$

TABLE 7.8 Engagement and patient preferences, 2016360

TABLE 7.9 Use of electronic medical records, 2015361

$\begin{array}{lll}\text { TABLE 7.10 Indicators of administrative efficiency, } 2015 & 377\end{array}$ 
Figures

FIG. 1.1 Map of the United States 3

FIG. 1.2 Tax revenue as a percentage of GDP, OECD countries, 2015

FIG. 1.3 Percentage of the population unemployed in the United States, by race/ethnicity, 1980-2016

FIG. 1.4 Percentage of the population below the poverty level in the United States, by race/ethnicity, 1980-2016 9

FIG. 2.1 Organization of the US health system in 2020

FIG. 2.2 Organization of the Department of Health and Social Services 44

FIG. 3.1 Growth in real national health expenditures, selected years 100

FIG. 3.2 Current health expenditures as a share (\%) of GDP in OECD countries, 2019

FIG. 3.3 Trends in current health expenditures as a share (\%) of GDP in the United States and selected countries, 2000 to latest available year

FIG. 3.4 Public expenditures on health as a share (\%) of current health expenditures in OECD countries, 2019

FIG. 3.5 Current health expenditures in US\$ PPP per capita in OECD countries, 2019

FIG. 3.6 Variation among US states in health expenditures per capita, 2014

FIG. 3.7 Financial flows

FIG. 3.8 Health plan types offered by employers, among employers offering health benefits, 2017

FIG. 3.9 Percentage of covered workers enrolled in an HDHP/ HRA or HAS-qualified HDHP, 2006-2017

FIG. 3.10 Average annual increases in premiums for family coverage compared to other indicators, 2000-2019

FIG. 3.11 Cumulative increases in family premiums, worker contributions to premiums, inflation and worker's earnings, 2000-2019

FIG. 3.12 Average general annual health plan deductible for single coverage, by firm size, 2006-2019 
FIG. 4.1 Median average age of hospital plants in the United States, 1995-2015

FIG. 4.2 Hospital profit margins, 1995-2016

FIG. 4.3 Number of beds in US community hospitals, psychiatric institutions and nursing homes per 1000 population, 1970-2015 183

FIG. 4.4 Occupancy rates in acute-care hospitals in seven OECD countries, 1990-2016

FIG. 4.5 Distribution of outpatient vs inpatient revenues in hospitals, 1995-2016

FIG. 4.6 Physicians per 1000 population in seven OECD countries, 2000-2017

FIG. 4.7 Nurses per 1000 population in seven OECD countries, 2002-2016

FIG. 5.1 Healthcare pathways for insured patients 227

FIG. 5.2 Healthcare pathways for uninsured patients 231

FIG. 7.1 Health insurance coverage of the under-age 65 population by poverty level, 2017

FIG. 7.2 Health insurance coverage of low-income adults under age 65 and children, 2017

FIG. 7.3 Barriers to healthcare among adults aged 18-64, by insurance status, 2017

FIG. 7.4 Diagnosis of late-stage cancer: uninsured vs privately insured

FIG. 7.5 Percentage of population who spent $10 \%$ or more of income out-of-pocket, by top and bottom income quintiles, 2010

FIG. 7.6 Cancer survival rates for breast cancer (women), leukaemia (children) and colon cancer among eight countries since 2000

FIG. 7.7 In-hospital mortality (within 30 days of admission) among eight countries

FIG. 7.8 Avoidable hospital admission rates for asthma, chronic obstructive pulmonary disease, congestive heart failure, hypertension and diabetes-related complications among eight countries since 2005

FIG. 7.9 Physician satisfaction with practising medicine among 10 countries, 2015 
FIG. 7.10 The time practices spend on insurance issues or claims payments is a major problem, 2015

FIG. 7.11 Preventable and amenable mortality since 2000 among eight countries

FIG. 7.12 Mortality amenable to healthcare by race, state variation, 2009-2010

Boxes

BoX 2.1 Efforts to provide universal health coverage in the United States 39

B0X 2.2 The Patient Protection and Affordable Care Act 46

B0X 3.1 Overview of the federal government budgeting process 110

B0X 3.2 Insurers and health plans 112

$\begin{array}{lll}\text { BOX 3.3 Accountable Care Organizations } & 129\end{array}$

B0X 3.4 What are the key gaps in coverage? 156

BoX 3.5 Medicare Part A and Part B payment mechanisms 164

BOX 4.1 The US healthcare workforce 203

B0X 5.1 Example of an insured person's healthcare pathway 228

BOX 5.2 Example of an uninsured person's healthcare pathway 232

BOX 5.3 Core public health functions and essential services 235

BOX 5.4 US public health service agencies 236

BoX 7.1 Shorter Lives, Poorer Health 364 
This page intentionally left blank 